\section{The formation of tooth brushing automaticity of 7-8 year-old children using appreciative inquiry (Ai) approach}

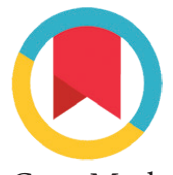

CrossMark

\author{
Lisa Prihastari, ${ }^{*}$ Zaura KA. Matram, Anton Rahardjo
}

\title{
Abstract
}

Objective: To measure the effectiveness of the appreciative inquiry (Al) approach for the formation of tooth brushing automaticity of children in school for 2 months.

Material and Methods: Randomized-Community Trial with a school-based supervised tooth brushing program for two months. Automaticity was measured with self-report behavior automaticity index (SRBAI) and intraoral examination was done with patient hygiene performance modified index (PHP-M)at the baseline, after 1 month and after 2 months.

Results: automaticity proportion was significantly higher in the Al group (63.8\%) compared to conventional group (22.1\%) $(P=0.000$; $\mathrm{OR}=11.9,95 \% \mathrm{Cl}=4.794-29.497)$.

Conclusion: appreciative inquiry was more effective than conventional health education approach for tooth brushing behavior change.
Department of Preventive and Public Health Dentistry, Faculty of Dentistry, University of YARSI, Central Jakarta, Indonesia
*Correspondence to: Lisa Prihastari, Department of Preventive and Public Health Dentistry, Faculty of Dentistry, University of YARSI, Central Jakarta, Indonesia lisa.prihastari@yarsi.ac.id

Received: 22 August 2019

Revised: 5 January 2020

Accepted: 19 March 2020

Available Online: 1 April 2020

Keywords: Appreciative inquiry, Automaticity, Behavioral change, Habit, Tooth brushing

Cite this Article: Prihastari L, Matram ZKA, Rahardjo A. 2020. The formation of tooth brushing automaticity of 7-8 year-old children using appreciative inquiry (Ai) approach. Journal of Dentomaxillofacial Science 5(1): 22-27. D0I: 10.15562/jdmfs.v5i1.968

\section{Introduction}

Brushing teeth properly is the easiest preventive action to reduce the number of dental caries. Based on the 2013 RISKESDAS data, the number of Indonesian people who have the ability to brush their teeth properly is still very low, only $2.3 \%{ }^{1}$ The school based tooth brushing program that has been implemented by the government through the UKGS in community health centers (Puskesmas) and private institutions supported by dental education institutions is still not effective enough to build the proper tooth brushing behavior. One reason is because forming tooth brushing behavior requires long processes and stages, and it is influenced by many factors.

Early childhood caries prevention, in this case the oral self-care education, should be initiated primarily for children of elementary school age (4-12 years) because of three fundamental things, namely the formation of habits, development of skill and vulnerable age (susceptibility). ${ }^{2}$ The formation of the habit of brushing teeth becomes more difficult to be influenced in adolescence period. ${ }^{3}$ The formation of habit of brushing teeth in elementary school age should be done from the age of 7-8 years. It is a vulnerable age for permanent dental caries related to the time of eruption of incisive teeth and first molar. In addition, at this age, children's motor development in brushing teeth has begun to form, mainly in terms of how to hold the brush and how to move the brush. ${ }^{4}$
Habit formation in children according to several studies in the field of psychology is characterized by the formation of automaticity or a person's automatic response to a trigger that arises due to repetition and consequences. ${ }^{5,6}$ The results of a recent study conducted by PhillipaLally et al in 2009 to 96 participants who made behavioral change efforts showed that the average time needed to adopt behaviors automatically (automaticity) ranged from 18 to 254 days. ${ }^{6}$ This indicates that the time needed to form a new habit is varied depending on the level of complexity or level of difficulty. Furthermore, the average minimum time needed for habit formation is characterized by the presence of automaticity ranging from 66 days to approximately two months. Repetition of the new behavior must be done consistently, especially in the early days because it will help to speed up the process of the new habit installation. ${ }^{5,7}$

Gardner et al. ${ }^{5}$ validated the four-item scale for automaticity measurement using the SRBAI (SelfReport Behavioral Automaticity Index) questionnaire. SRBAI is proven to be reliable and highly correlated with the Self-Report Habit Index (SRHI) developed is a standard questionnaire to measure someone's habit formation, and it is sensitive to changes. ${ }^{5}$

Appreciative inquiry is an approach that develops the concept of positive change that can change the sick paradigm to the healthy paradigm and can 
foster one's intrinsic motivation. This approach is proven to increase the effectiveness of behavior change programs. The concept of appreciative inquiry has been applied in various world organizations $^{8,9}$ and in the field of healthcare, especially nursing. ${ }^{10-12}$ Appreciative comes from the basic word appreciate which means an action to understand the best thing of an individual or the support of individual's strength, success and potential given by his surroundings. While inquiry originates from the basic inquire, which means the act of exploring and discovering; asking questions to broaden views of new possibilities and potential. ${ }^{13}$

In the field of healthcare, AI has been applied to improve the quality and management of health clinics and hospitals, ${ }^{14}$ to reduce puerperal infections in India, ${ }^{15}$ to promote oral care in nursing, ${ }^{16}$ as an evaluation approach in the field of nursing education, ${ }^{17}$ and others. The basic step of Appreciative Inquiry is the 5-D cycles, which are definition, discovery, dream, design and destiny.

\section{Material and Methods}

The design of this study was community trial with pre post control group. This experimental research included a group of 7-8 years-old elementary school children in Madiun City East Java. The study was conducted from February 2016 to April 2016. The students were divided into a treatment group and a control group. Samples were selected using Multistage Random sampling with the final research subjects of 164 children, consisting of 77 girls and 87 boys with a dropout rate of $7.34 \%$. The chart of research subject participation can be seen in figure 1. Inclusion criteria were: school-aged children of 7-8 years old, never get a daily joint tooth brushing program, physically and mentally healthy, parents are willing to sign an informed consent, the teeth condition matches the personal hygiene performance index (PHP-M) criteria. Exclusion Criteria were children who cannot participate until the end of the program, children whose parents do not collect questionnaires, uncooperative children during the program, children with disabilities or special needs.

The Appreciative Inquiry (AI) program was written in the form of a module that had been consulted beforehand to educational psychology experts. AI program was given to the experimental group. The teachers were given trainings before the implementation. The program implementation was divided into three meetings based on the 5D cycle. In the control group, the subjects only received a conventional DHE program. It was only one meeting using videos and teaching aids. After the two groups received a training program, tooth brushing activities were held together in school for approximately 60 days to initiate the formation of a new habit of brushing teeth.

An intraoral examination was carried out by one examiner, with the results of the kappa intra observer calibration test of 0,83 which was very good. Intraoral examination was carried out to determine oral hygiene status by measuring the PHP-M index (Patient Hygiene Performance Modified) of the subjects before joining the tooth brushing training program, after 1 month of the program and after 2 months the program took place. The values of PHP-M index before and after the program of each group were compared.

Data regarding the automaticity score was collected through the SRBAI questionnaire (self -report behavioral automaticity index) which was modified by the researcher. The validity and reliability of the questionnaire had tested every week for two months as the tooth brushing program progressed. The comparative tests of numerical non-normal distribution, two unpaired groups of Mann-Whitney test, Friedman test and Chi square test were conducted.

\section{Results}

The sociodemographic data from the questionnaire showed that the largest proportion of children were at the age of 8 , which were $51.8 \%$ and the remaining $48.2 \%$ were at the age of 7 . For the gender variable, $53 \%$ of the participants were boys and $47 \%$ were girls. Furthermore, for the variable of birth order, $44,5 \%$ of the children were the first child, $40.3 \%$ were the last or youngest child and $15.2 \%$ were the middle child in their family. In terms ofSociodemographic data of the parents, for the variable of mother's last education, showed that $51.8 \%$ had achieved undergraduate/diploma degree, $44.5 \%$ were high school/equivalent graduates and 1.2\% finished junior high school/equivalent and below. For the employment status of the mother, $61 \%$ were working and $39 \%$ were unemployed. For the economic status variable, $80.5 \%$ were in the middle class, $18.3 \%$ were upper class and the remaining $1.2 \%$ belonged to lower class.

The intra-oral examination results can be seen in Table 1. It shows that the results of the MannWhitney test on the difference score of the Modified Personal Hygiene Performance index (PHP-M). The score was obtained from the PHP-M score before brushing minus the score after brushing at the baseline, after 1 month and after 2 months the program took place. The table shows that in the experimental group the score increased when compared to baseline, after 1 month and after 2 months of the program. However, it was different 
in the control group. There was an increase after first month follow-up compared to the baseline. However, subsequently there was a decrease after the second month follow-up. The increase in the PHP-M score showed that the subjects could clean more plaque areas.

The results in table 2 show that there were significant differences in the difference of the PHP-M index scores at the three examination times in both the experimental and control groups. To know the difference between the times of the examination, the Wilcoxon posthoc test was conducted. There was a significant difference in the PHP-M index score of the experimental group at baseline compared with first month follow-up $(\mathrm{p}=0.000)$, baseline compared to second month follow-up $(\mathrm{p}=0.000)$ and first month follow-up compared to the second

Table 1 Results of the Mann-Whitney analysis test of difference in PHP index score

\begin{tabular}{llcc}
\hline Variable PHP index & Median (minimum-Maximum) & P value \\
\hline \multirow{2}{*}{ Baseline } & Experimental & $0.67(0.17-1,17)$ & 0.521 \\
& Control & $0.67(0.17-1,17)$ & \\
Month 1 & Experimental & $1(0.17-2.67)$ & $0.023^{*}$ \\
& Control & $1.5(0.00-2.50)$ & \\
Month 2 & Experimental & $2(0.83-3.17)$ & $0.001^{*}$ \\
& Control & $1(0.33-2.34)$ & \\
\hline
\end{tabular}

${ }^{*}$ significance values indicate that there are significant differences $(\mathrm{p}<0.05)$

Table 2 The results of the friedman analysis test on the difference in average PHP-M index scores of the experimental and control groups

\begin{tabular}{|c|c|c|c|c|}
\hline & \multicolumn{4}{|c|}{ PHP-M Index } \\
\hline & \multicolumn{2}{|c|}{ Experimental group } & \multicolumn{2}{|c|}{ Control group } \\
\hline & $\begin{array}{c}\text { Median } \\
\text { (Min-Max) }\end{array}$ & $P$ value & $\begin{array}{c}\text { Median } \\
\text { (Min-Max) }\end{array}$ & $P$ value \\
\hline Baseline & $0.67(0.17-1,17)$ & 0.000 & $0.67(0.17-1,17)$ & 0.000 \\
\hline Month 1 & $1(0.17-2.67)$ & & $1.5(0.00-2.50)$ & \\
\hline Month 2 & $2(0.83-3.17)$ & & $1(0.33-2.34)$ & \\
\hline
\end{tabular}

*significance values indicate that there are significant differences $(\mathrm{p}<0.05)$

Table 3 Mann-Whitney Analysis Test of the Increase of automaticity scores of tooth brushing behavior in the experimental and control groups

\begin{tabular}{lccc}
\hline & \multicolumn{3}{c}{ Automaticity score } \\
\cline { 2 - 4 } & \multicolumn{3}{c}{ Median (Min-Max) } \\
\cline { 2 - 4 } Group & $\begin{array}{c}\Delta \text { Baseline - } \\
\text { month }\end{array}$ & $\begin{array}{c}\Delta \text { Baseline - 2 } \\
\text { months }\end{array}$ & $\begin{array}{c}\Delta \text { 1 month - 2 } \\
\text { months }\end{array}$ \\
\hline Experimental & $16(10-20)$ & $6(0-14)$ & $8(1-16)$ \\
Control & $13(6-18)$ & $3(0-9)$ & $6(2-11)$ \\
P-Value & $0.037^{\star}$ & 0.000 & 0.000 \\
\hline
\end{tabular}

* significance values indicate that there are significant differences $(\mathrm{p}<0.05)$ month follow-up ( $\mathrm{p}=0.000)$. In the control group, there were also significant differences at the baseline compared to first month follow up ( $\mathrm{p}=0.000$ ), baseline compared to second month follow up $(\mathrm{p}=0.000)$ and first month follow up compared with second month follow up $(\mathrm{p}=0.000)$.

The modification of the SRBAI (Self Report behavior Automaticity Index) questionnaire filled out by parents to find out the automaticity score for brushing teeth of the children in the experimental group and the control group at baseline, after 1 month and 2 months follow up is shown in graph 2 .

The results of the questionnaire were tested using Kolmogorov-Smirnov normality test to find out the distribution of data. The result was that the data was not normally distributed in the three examination times ( $p>0.05)$ in each group. Figure 1 shows that in the experimental and control groups there is an increase in automaticity scores after 1 month follow-up and after 2 months follow-up compared to the baseline. To find out whether there were differences in the total score of the questionnaire between the experimental and control groups, the Mann-Whitney test was conducted. The results can be seen in table 3 .

Table 3 shows that there are significant differences in the increase in automaticity scores between the experimental group and the control group at baseline compared to examination after 1 month, baseline compared to examination after 2 months and examination after 2 months compared to examination after 1 month. The experimental group obtained higher score compared to the control group. Furthermore, to find out whether there were differences in the three examination times in each group, Friedman's analysis test was carried out. The results can be seen in table 4 . There were significant differences in the difference of automaticity scores between examinations at baseline, after 1 month and after 2 month in both the experimental and control groups.

The Wilcoxon posthoc test found that there was a significant difference at baseline compared with 1-month follow-up $(\mathrm{p}=0.000)$, baseline compared with 2 months follow-up $(\mathrm{p}=0.000)$ and 1 -month follow-up compared with 2 months follow-up $(\mathrm{p}=0.000)$. In the control group, there were also significant differences at baseline compared with 1 month follow-up ( $\mathrm{p}=0.000)$, baseline compared with 2 months follow-up $(\mathrm{p}=0.000)$ and 1 month follow-up compared with 2 months follow-up $(p=0.000)$.Substantially, the formation of automaticity occurs when the number of scores is in the range of 16-20. To see the frequency distribution of automaticity at the baseline, 1 month and 2 months in the experimental and control groups, see table 5 below. 
Table 4 Test of friedman analysis of difference in automaticity tooth brushing score in the experimental and control groups

\begin{tabular}{lccccc}
\hline & \multicolumn{4}{c}{ Automaticity } \\
\cline { 2 - 3 } & \multicolumn{2}{c}{ Experimental Group } & & \multicolumn{2}{c}{ Control Group } \\
\cline { 2 - 3 } \cline { 5 - 6 } & $\begin{array}{c}\text { Median } \\
(\text { Min-Max) }\end{array}$ & P value & & $\begin{array}{c}\text { Median } \\
\text { (Min-Max) }\end{array}$ & P- value \\
\hline Baseline & $8(4-12)$ & 0.000 & & $6(4-12)$ & 0.000 \\
Month 1 & $14(4-18)$ & & & $11(6-15)$ & \\
Month 2 & $16(10-20)$ & & & $13(6-18)$ & \\
\hline
\end{tabular}

* significance values indicate that there are significant differences $(\mathrm{p}<0.05)$

Table 5 Distribution of Frequency of Tooth Brushing Automaticity status in the experimental and control groups

\begin{tabular}{|c|c|c|c|c|c|c|}
\hline \multirow{3}{*}{$\begin{array}{l}\text { Automaticity } \\
\text { Status }\end{array}$} & \multicolumn{4}{|c|}{ Group } & & \\
\hline & \multicolumn{2}{|c|}{ Experimental } & \multicolumn{2}{|c|}{ Control } & \multicolumn{2}{|c|}{ Total } \\
\hline & $n$ & $\%$ & $n$ & $\%$ & $\mathbf{N}$ & $\%$ \\
\hline \multicolumn{7}{|l|}{ Baseline } \\
\hline Yes & 0 & $0 \%$ & 0 & $0 \%$ & 0 & $0 \%$ \\
\hline No & 69 & $100 \%$ & 95 & $0 \%$ & 164 & $100 \%$ \\
\hline \multicolumn{7}{|l|}{1 month } \\
\hline Yes & 25 & $36.2 \%$ & 0 & $0 \%$ & 25 & $1.2 \%$ \\
\hline No & 44 & $63.8 \%$ & 95 & $0 \%$ & 139 & $98.8 \%$ \\
\hline \multicolumn{7}{|l|}{2 months } \\
\hline Yes & 44 & $63.8 \%$ & 21 & $22.1 \%$ & 65 & $39.6 \%$ \\
\hline No & 25 & $36.2 \%$ & 74 & $77.9 \%$ & 99 & $60.4 \%$ \\
\hline
\end{tabular}

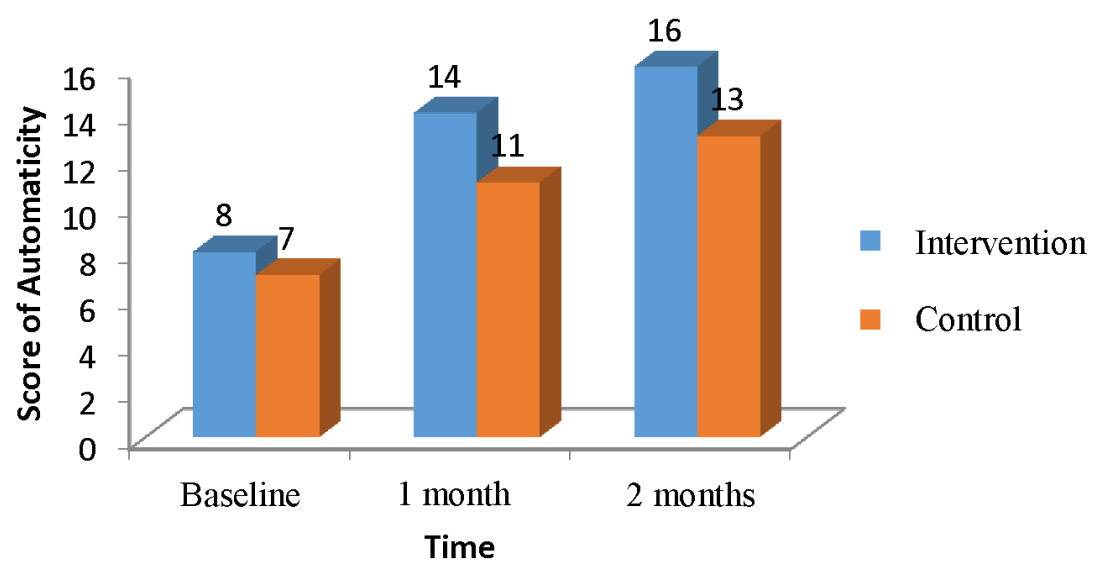

Figure 1 The difference in the average score of automaticity

To see if there were significant differences in table 5, a chi-square test was conducted for children who already gained automaticity and children who had not gained automaticity after 2 months of intervention in the experimental and control groups. students who reached the automaticity stage were $63.8 \%$ or 44 children. In the control group, there were only $22.1 \%$ or 21 children that reached the automaticity stage. For children who had not reached the automaticity stage, there were $36.2 \%$ or 25 children in experimental group and $77.9 \%$ or 74 children in control group. Statistically, there was a relationship between the treatment group and automaticity $(p=0.000)$ with the OR calculation of 6.2 and RR calculation of 2.9 figure 2 .

\section{Discussion}

The advantage of a community trial study is that this design is suitable for multifactorial diseases, one of which is also caused by social factors, and for research that targets the community. However, the disadvantage of this study is that the design can only be applied to small communities. If it is done randomly in large communities, it is usually not practicable. In addition, it is also difficult to isolate the community and make intervention, in this case appreciative inquiry (AI), as the major factor in changing the behavior of tooth brushing in children despite other social factors that might be influential.

The effectiveness of appreciative inquiry (AI) in this study was measured by the presence or absence of automaticity in the experimental group compared to the control group and how long it would take to form automaticity. According to the assumptions in the community, a new behavior can be adopted after 21 days, whereas according to a recent study by PhillypaLally, the minimum average time span needed for habitual automation as a sign of adoption is 66 days or approximately 2 months. ${ }^{5}$ Based on the measurement results of the difference in the PHP-M index score at the baseline, the experimental group and the control group scores were not significantly different. It showed that children's ability to brush teeth to remove plaque in the experimental and control groups was equal before the treatment.

Significant differences began to appear after 1 month and 2 months of follow-up. Each group experienced an increase in the PHP-M score compared with the baseline. In the experimental group, the increase occurred at the first month of follow-up and kept increasing on the second month of the follow-up. It was different from the control group which experienced an increase at the first month but subsequently the score decreased after 2 months of follow-up. The results of the Mann Whitney test also showed a significant difference between groups at baseline examination compared with the examination after 2 months and examination after 1 month compared with the examination after 2 months. The temporary increase occurred in the control group probably was caused by the Hawthorne effect or reactivity in the control group 


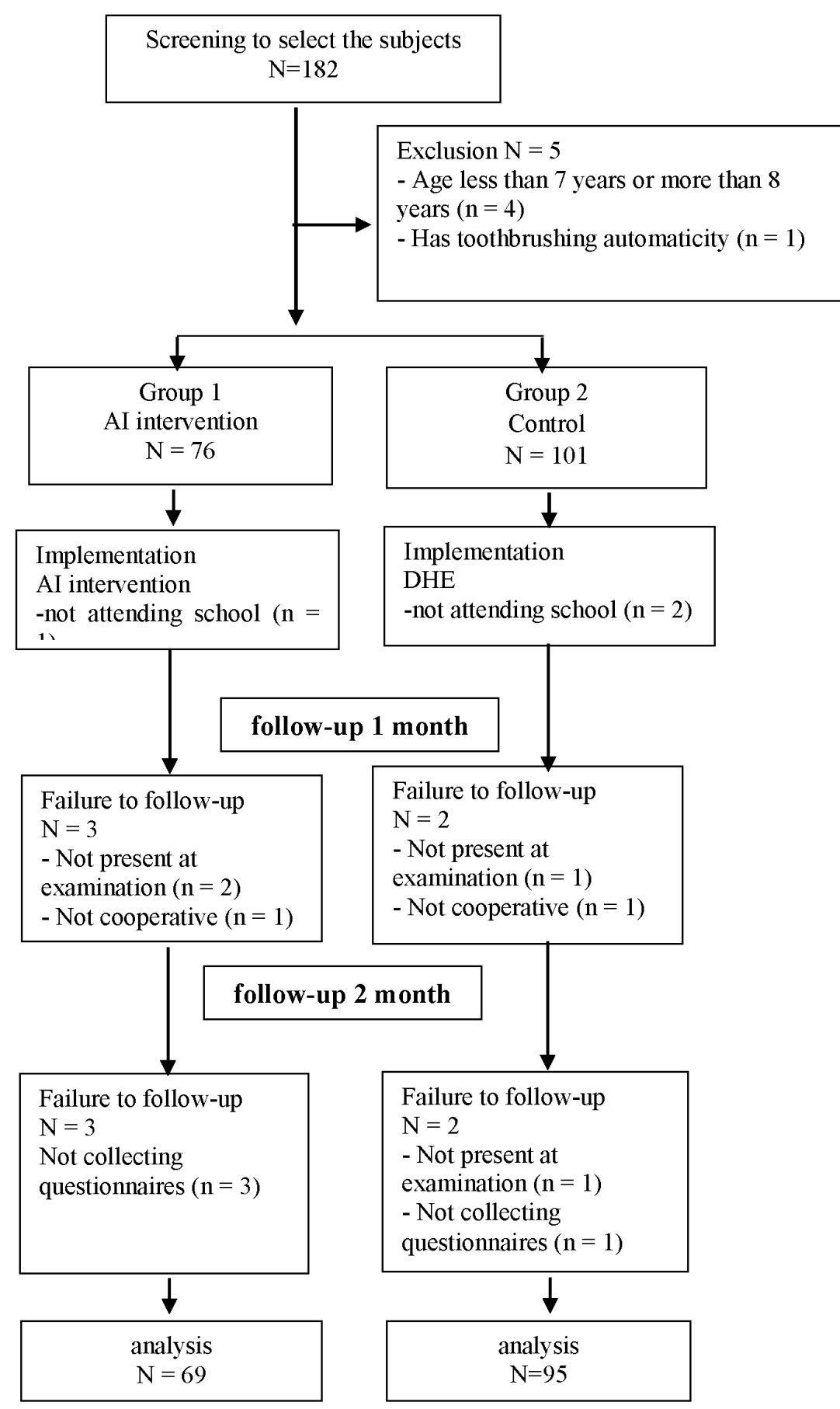

Figure 2 Flowchart of research subject participation

because they were being observed during the study. It motivated the research subjects to improve the way they brushed their teeth.

In addition, the control group was given DHE counseling by the researchers through the conventional lecturing method. DHE counseling with the audiovisual method itself has been proven in several studies to provide changes in knowledge, attitudes, brushing skills and plaque scores of the research subjects. ${ }^{18}$ In addition, it was possible that the tooth brushing program which was carried out every day at school for 2 months influenced the behavior changes of the research subjects. Habit itself can arise with the existence of behavior that is constantly repeated. ${ }^{4}$

Habit formation was primarily continuous repetition including the formation of tooth brushing habit. ${ }^{19-20}$ Children are easily subjected to behavioral changes through repetition and reinforcement than adults. ${ }^{21-22}$ Based on the results of the automaticity status analysis test using Mann Whitney, it was found that the baseline measurements initially did not show significant differences in the experimental and control groups. Both groups were in the same automaticity status, all children (100\%) did not have automaticity status.

After 1-month follow-up, there were $36.2 \%$ of the children obtained the automaticity in the experimental group. For the control group, no children (0\%) gained automaticity. After 2 months, children who reached the stage of automaticity in the experimental group increases to more than half, reaching $63.8 \%$. In the control group, there were only $22.1 \%$. This showed that children in the intervention group achieved the automaticity stage 2 times faster than children in the control group. Based on the OR chi square the research subjects in the intervention group had 6.2 times possibility of experiencing automaticity, compared to the subjects in the control group. RR values showed that the opportunity for automaticity in the experimental group was 2.9 times greater compared to that of control group.

In this study, 2 months or approximately 61 days (joint toothbrushes simultaneously was carried out from March 1, 2016 to April 30, 2016) were still not enough to build the automaticity of all research subjects in both the experimental group and the control group. Therefore, the average time needed for children aged 7-8 years to reach the automaticity stage in this study cannot be calculated. The results of this study indicate that even though the number of children obtaining automaticity reached 65 children $(39.6 \%)$ out of a total of 164 samples, only 27 children (17.1\%) had the ability to brush the entire region correctly. In Judah et al research in 2012, it needed approximately 8 months to form automaticity of flossing habit of their research subjects of young women aged 26-28 years. ${ }^{23}$

The ability of children to brush their teeth properly can inhibit their caries development. Caries can affect the mental health of children, children with high DMFT have abnormal mental health. ${ }^{24}$ Programs to instill this behavior are very important, one of them is through the appreciative inquiry (AI). The AI and tooth brushing program in schools act as behavioral change programs for the children. Through the AI program, children improve their cognitive aspects in terms of dental health knowledge at the definition stage, where 
DHE material is provided with audiovisual media just as in the control group is given. The improvement of the affective aspects in terms of awareness and attitudes towards dental health was carried out in the discovery and dream stages through the excavation and planting positive experiences on dental health. Therefore, children feel that they can achieve the goals of obtaining healthy teeth in the future. Furthermore, the skill of brushing teeth was improved at the destiny stage. Children did a simulation of brushing their teeth with the correct method, rinsing only once and using a timer for 2 minutes.

For the consequences caused by the tooth brushing automaticity behavior is that the child must change his tooth brushing habit in the morning with the habit of brushing the teeth together at school before starting the lesson. Night tooth brushing before going to bed is usually more difficult to do because children are usually lazy and forgetful. During the design stage, trainers and children have made plans so children always remember to brush their teeth before going to bed by making a poster to be attached in their room, asking their family members to remind them, making a tooth brushing alarm and filling out the daily report book that must be signed by the parents if they brush their teeth at night.

\section{Conclusion}

This study that the appreciative inquiry intervention program is more effective than the conventional dental health education program in forming tooth brushing behavior for children aged 7-8 years.

\section{Acknowledgment}

The authors would like to thank LPDP Institution of Indonesian Ministry of Finance for financial support of the research and the lectures dental public health departement from Dentistry Faculty University of Indonesia for valuable advice and comments.

\section{Conflict of Interest}

The authors report no conflict of interest.

\section{References}

1. KementerianKesehatan RI. RisetKesehatan Daerah 2013. Jakarta: Litbang Dinkes; 2013. p. 150-166.

2. Cooper AM, Margaret C, Dugdill L. Challenges in oral health behavioral intervention studies in children. Pragmatic Observ Res 2014;5: 43-51.
3. Sandström A, Cressey J, Stecksén-Blicks C. Toothbrushing behaviour in 6-12 years old. Int J Paediatr Dent 2011;21: 43-49.

4. Sharma S, Yeluri R, Jain A, et al. Effect of toothbrush grip on plaque removal during manual toothbrushing in children. J Oral Sci 2012;54: 183-190.

5. Gardner, B. Habit as automaticity, not frequency. Euro Health Psychol 2012;14: 32-36.

6. Lally P, Van-Jaarsveld CH, Potts HW, et al. How are habits formed: modelling habit formation in the real world. Eur J Soc Psychol 2010;40: 998-1009.

7. Wood W, Neal DT. A new look at habits and the habit-goal interface. Psychologic Rev 2007;114: 843-863.

8. Cooperrider DL, McQuaid M. The positive arc of systematic strengths: how appreciative inquiry and sustainable designing can bring out the best in human systems. JCC 2012;46: 71-102.

9. Trajkovski S, Schmied V, Vickers M, et al. An appreciative inquiry approach to practice improvement and transformative change in health care settings. Contemp Nurse 2013;54: 95-100.

10. Sidebotham M, Fenwick J, Rath S, et al. Midwives' perceptions of their role within the context of maternity service reform: an appreciative inquiry. Women Birth 2015;28: $112-20$.

11. Carter CA, Ruhe MC, Weyer S, et al. An appreciative inquiry approach to practice improvement and transformative change in health care settings. Q Manage Health Care 2007;16: 194-204.

12. Trajkovski S, Schmied V, Vickers M, et al. Implementing the $4 \mathrm{D}$ cycle of appreciative inquiry in health care: a methodological review. J Adv Nurs 2013;69: 1224-1234.

13. Williams RF. Survey guided appreciative inquiry: a case study. Org Develop Pract 1996;28: 43-51.

14. Bushe GR. Appreciative Inquiry is not (just) about the positive. OD Pract 2007: 30-35.

15. Hussein, Julia, et al. "The effect of surveillance and appreciative inquiry on puerperal infections: a longitudinal cohort study in India." PloS one 2014;9: e87378.

16. Cooperider DL, Whitney $\mathrm{D}$, et al. Appreciative inquiry handbook. 2nd ed. Brunswick Crown Custom Publishing; 2008.

17. Haar VD, Hosking D. Evaluating appreciative inquiry: a relational constructionist perspective. Human Relations 2004;57: 1017-1036.

18. Blake H, Dawett B, Leighton P, et al. Schoolbased educational intervention to improve children's oral healthrelated knowledge. Health Promot Pract 2015;16: 57182.

19. Pujar P, Subbareddy VV. Evaluation of the tooth brushing skills in children aged 6-12 years. Eur Arch Paediatr Dent 2013;14: 213-219.

20. Robert A. Tooth brushing as routine behavior. Int Dent J 2007;57: 1-13.

21. Lally P, Gardner B. Promoting habit formation. Health Psychology Review. Advance online publication. 2012;7(Suppl 1): S137-S158.

22. Abdul H, Khan MK, SufiaShamta, et al. The role of repetition and reinforcement in school-based oral health education-a cluster randomized controlled trial. BMC Public Health 2016;16: 1-11.

23. Judah G, Gardner B, Aunger R. Forming a flossing habit: an exploratory study of the psychological determinants of habit formation. Br J Health Psychol, 2013;18: 338-353.

24. Anwar A. Correlation between mental health and caries status in Primary School Students. J Dentomaxillofac Sci 2018;3: 108-111.

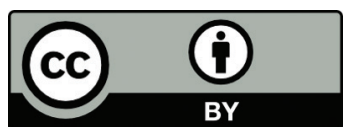

This work is licensed under a Creative Commons Attribution 